\title{
EAl Endorsed Transactions

\section{Developing a Mathematical Model of a Horizontal Looper Taking into Account the Features of a Steel Strip}

\author{
Ye.V. Kuntush ${ }^{1, *}$, I.V. Breido ${ }^{1}$ and A.M. Zyuzev ${ }^{2}$ \\ ${ }^{1}$ Karaganda State Technical University, Karaganda, Kazakhstan \\ ${ }^{2}$ Ural Federal University n.a. the First President of Russia B.N. Yeltsin, Yekaterinburg, Russia
}

\begin{abstract}
Modern cold rolling mills include devices that form a reserve of strip to ensure the continuous operation of the line. Such devices include a horizontal looper containing a direct current drive. The disadvantage of the existing horizontal looper is significant oscillations of the metal strip in the process of its filling, with the maximum amplitude of oscillations occurring when the strip is completely filled. To study the oscillatory processes in the strip, a model of an electromechanical system has been developed. The necessity of taking into account mechanical properties of the steel strip in the development of a model of an electromechanical system has been substantiated. Mathematical and simulation models of a horizontal looper were developed in two extreme positions. The simulation models have been implemented in the MatLab software package. The results of simulation studies showed satisfactory convergence of the experiments with the physical process.
\end{abstract}

Keywords: electromechanical system, mathematical model, oscillations, elastic coupling.

Received on 12 November 2019 , accepted on 25 March 2020, published on 26 March 2020

Copyright (C) 2020 Ye.V. Kuntush et al., licensed to EAI. This is an open access article distributed under the terms of the Creative Commons Attribution licence (http://creativecommons.org/licenses/by/3.0/), which permits unlimited use, distribution and reproduction in any medium so long as the original work is properly cited.

doi: 10.4108/eai.13-7-2018.163842

"Corresponding author. Email: elena_kuntush@mail.ru

\section{Introduction}

Modern high-speed strip processing lines require additional devices that form a reserve of metal to ensure the continuous operation of the line [1].

Among such lines there is a line of the unit of continuous hot-dip galvanizing of the ArcelorMittal Temirtau JSC.

This line is divided into three zones according to the nature of the speed of strip movement: the input, the technological and the output ones. The main zone is the technological zone in which the coating is placed. The speed of the strip in this zone is unchanged throughout the galvanizing process. The continuity of the process is ensured by the use of special loopers: strip accumulators located at the beginning and at the end of the technological zone. The input and the output zones are auxiliary. The speed of the strip in them varies depending on the course of the technological process [2].
The looper of the strip that is part of the basic mechanisms for continuous strip processing mills and "endless" cold rolling mills, although not involved in the processing of the strip, nevertheless, is a very crucial mechanism in the aggregates on which reliable operation their reliability and performance depend. The used loopers of horizontal and vertical types ensure the necessary reserve of strip between the parts of the process line [3] in the tensioned state. This reserve is used to ensure continuity of processing the strip in the middle of the unit during the technological stops of the head or tail parts, or to ensure continuous rolling during the technological stop of the head part [4].

The input looper of the continuous hot galvanizing unit is made in the horizontal version, the output looper in the vertical version.

The dynamics of vertical strip loopers have been studied quite well. The strip elastic properties in such loopers are manifested to a lesser extent than in horizontal ones $[2,5]$. 
At the same time horizontal loopers have specific properties associated with the length of the mechanism that imposes its own characteristics on the dynamic characteristics of this looper. Horizontal loopers are characterized by a relatively small height; few rollers are required when the carriage moves several tens of meters; constant tensioning the strip is easily ensured. The disadvantage of such devices is their large length; the complex design of the supporting rollers that must be taken aside when passing through the loop carriage; a more complicated direction of the strip than in tower devices [3, 4].

The aim of the work is developing a mathematical and simulation model of a horizontal looper that takes into account changes in the length and the mass of a strip in the looper and its elastic properties.

\section{Statement of the problem}

The input horizontal looper of the continuous hot galvanizing unit is designed to form the necessary strip margin when the input section stops for the period of welding the ends of the coils [5].

The practice of operation and analysis shows that the electric drive of the looper carriage has specific features that should be considered when designing its automatic control system. These features are associated with the variable length of the strip in the device itself, as well as with the presence of cable connection between the drive drum and the carriage.

In the course of observations it was found that the greatest oscillations occur with a short rope and a long strip, i.e. with the full looper. Consequently, the strip itself has the greatest impact on the dynamics of the electromechanical system of the looper in the process of filling the device.

When analyzing systems with elasticities, it is usually assumed that the elastic links are weightless and are characterized by constant coupling rigidity, i.e., the proportionality coefficient between the moment (force) and deformation $[6,7,8]$. In other cases, it is assumed that the material has a constant mass, but can change its stiffness due to temperature changes [9, 10]. Also, calculating of such type systems may have an assumption that the material has constant mass and rigidity [11]. But in this case this statement does not fit, since the peculiarity of the electromechanical system of the horizontal looper is changing the length of the strip located in the looper and, consequently, its mass and rigidity. These features make analyzed system outstanding from known systems with elastic couplings of industrial mechanisms. During the operation of a horizontal looper the length of the strip varies significantly: from $50,400 \mathrm{~mm}$ to $3,600,000 \mathrm{~mm}$. Therefore, to develop a model of the electromechanical system of a horizontal looper, it is necessary to take into account mechanical properties of the strip depending on the strip length, such as the moment of inertia, rigidity, etc. $[12,13]$.

The loop reserve in the looper can vary from $25-60 \%$ to $80-90 \%$, and sometimes even $100 \%$. Considering that the length of the looper is $89600 \mathrm{~mm}$, and the strip cross section varies from $0.4 \times 700 \mathrm{~mm}^{2}$ to $2 \times 1500 \mathrm{~mm}^{2}$, it can be stated that the strip mass varies considerably. The change is faster when removing the strip from the looper $(0.5 \div 1.5$ $\mathrm{min})$ than when it is accumulated $(1.5 \div 4.5 \mathrm{~min})$.

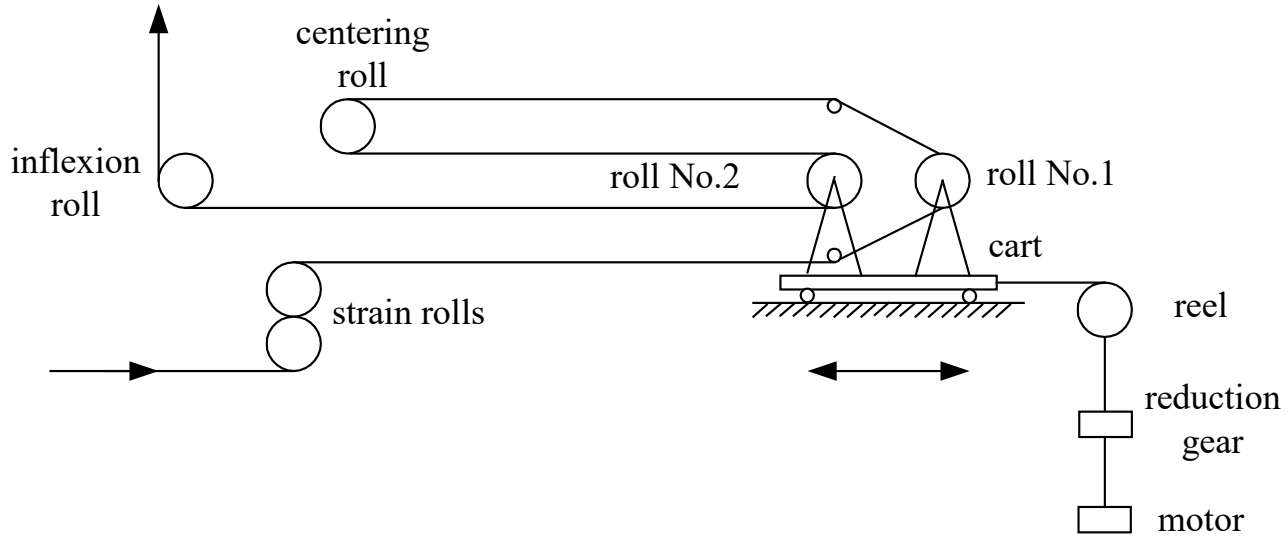

Figure 1. Kinematic diagram of a horizontal loop device

Figure 1 shows the kinematic diagram of a horizontal loop device. The strain, inflexion and centering rolls are fixed. Rolls No. 1 and No. 2 are mounted on a movable carriage. While carriage moves during the operation, the length of the steel strip is reduced to a minimum (empty device) or increases to maximum (filled device).
The strip mass in the looper varies from $48.683 \mathrm{~kg}$ (with an empty device and the smallest section) to $7709.832 \mathrm{~kg}$ (with a filled device and the largest section). The coefficient of inertia $\gamma$ varies slightly: from 1.059 to 1.163 .

With the coefficient $\gamma=1 \div 1.6$ the processes in the mechanical system with elastic couplings will be significantly oscillatory [14]. 
To develop a mathematical model of such a complex aggregate, it is necessary to have information about the mechanical parameters of the strip including elastic moments and frequencies of the strip oscillations. However, only 3 parameters of the horizontal looper are oscillated in the unit: motor current, linear velocity, and the loop reserve in the device. Measuring elastic moments in the branches of the strip and the distance between the branches is impossible due to the absence of necessary sensors.
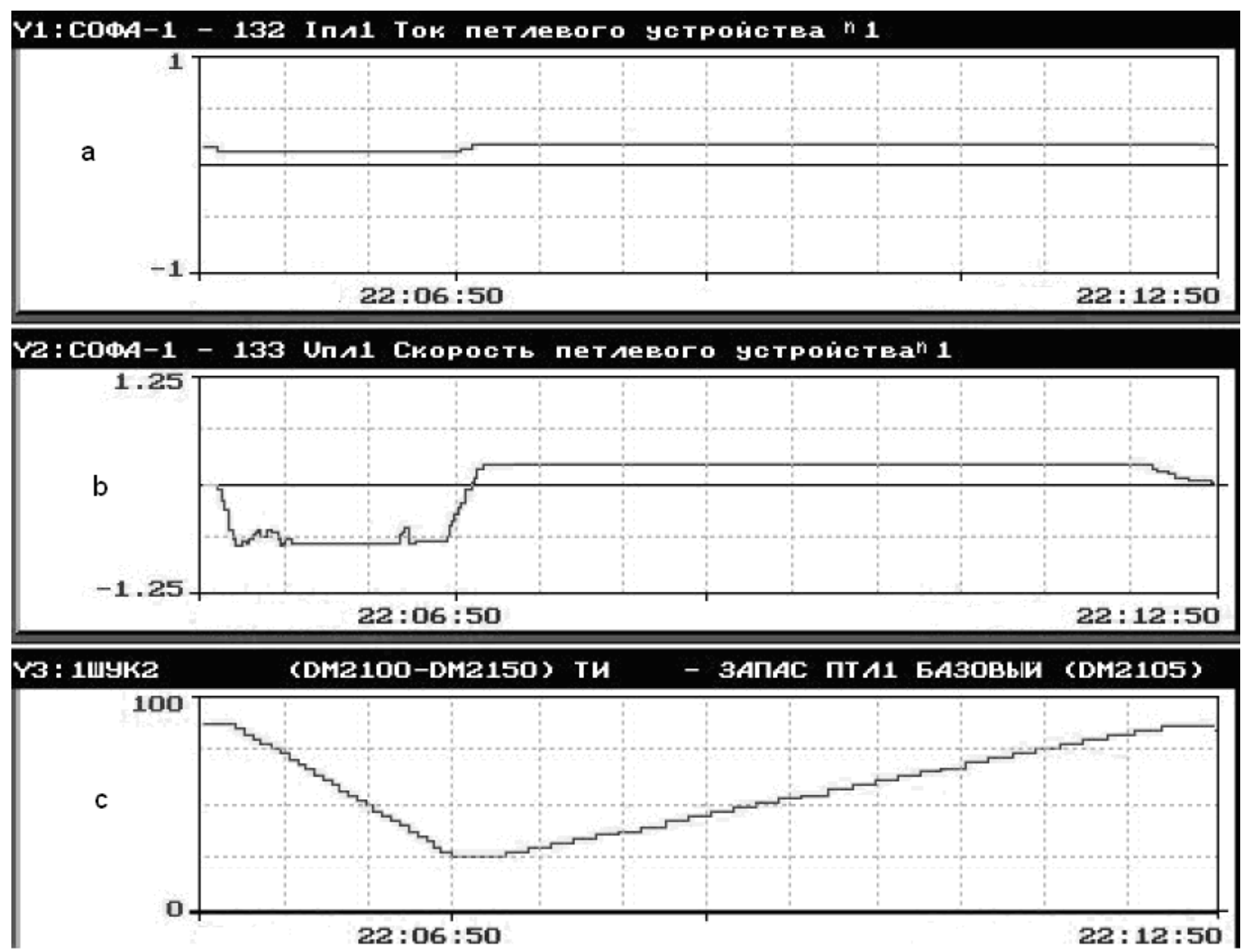

Figure 2. Changing the parameters of the horizontal looper

Figure 2 shows oscillograph trace of current (a), speed (b) and band margin (c). In transients of current and speed, as follows from Figure 2 ( $a$ and $b$ ), no current and speed fluctuations were detected. This can be explained by the small influence of mechanical vibrations on the electric part of the engine due to the small $\gamma$ and significant gear ratio (i $=33.85$ ).

In connection with the above-said, a partial experiment was carried out with the unit. A gauge was installed that was used to determine the amplitude of the strip oscillations. With the help of a stopwatch, the oscillation period was determined.

The distance between the parallel branches of a strip in the looper is $0.85 \mathrm{~m}$. Visual observations show that with a large strip length (the filled looper) there are vertical oscillations of a strip of large amplitude up to the collapse. i.e. the maximum amplitude value is limited by the distance between the parallel branches of a steel strip. The oscillation frequency is in the range of $0.3 \div 0.5 \mathrm{~Hz}$.

Consideration of the dynamics of the automatic control system of the electric drive of a real mechanism should be preceded by developing a model of the mechanism. On the one hand, this model should be sufficiently detailed in order the mathematical description based on it could give a reliable picture of dynamic processes. On the other hand, it should be fairly simple, so that the study of these processes on its basis could be implemented. The criterion for the admissibility of the accepted simplification should be a satisfactory agreement of the theoretical results with the results of the experiment [7].

\section{Developing the model}

Usually when considering systems in which the 
concentrated rotating masses of the engine rotor and the mechanism are interconnected through a gearbox and a long shaft, the following basic assumptions are made [12]:

(i) the forces and moments acting in the system are applied to concentrated masses that are not subjected to deformation;

(ii) the elastic links are weightless and are characterized by constant bond rigidity, i.e. by the coefficient of proportionality between the moment (force) and deformation;

(iii) the deformation of elastic links is linear and obeys the Hooke law;

(iv) the wave motion deformation can be neglected.

In most cases the presence of elasticity leads to the need of reducing the speed of the system.

The electric drive of the horizontal looper is a multimass system that cannot be reduced to a two-mass system $[8,15,16]$. When analyzing the electric drive system of a horizontal looper, it is necessary to take into account changing the rigidity of the strip as a distributed mechanical system with decreasing or increasing its length in the drive.
It is also necessary to take into account changing the mass of the steel strip, and, accordingly, its mechanical properties and the moment of inertia. At this it is necessary to take into account the connection through the rope between the carriage of the looper and the motor $[17,18,19]$.

At present the dynamics of the operation of horizontal loopers, methods for improving the dynamic properties of the mechanical part of the looper by means of an electric drive have not been studied sufficiently. Among the features inherent in the electromechanical system of the looper there should be noted its considerable complexity. It is manifested in the multi-element and multi-mass structure of the system, the presence of non-linear elements [20, 21, 22].

Modeling a looper at all points of its operation is quite complex, so let us consider two extreme positions: [23, 24]

(i) when a strip is fully brought into the looper;

(ii) when a strip is completely removed from the looper. 3.

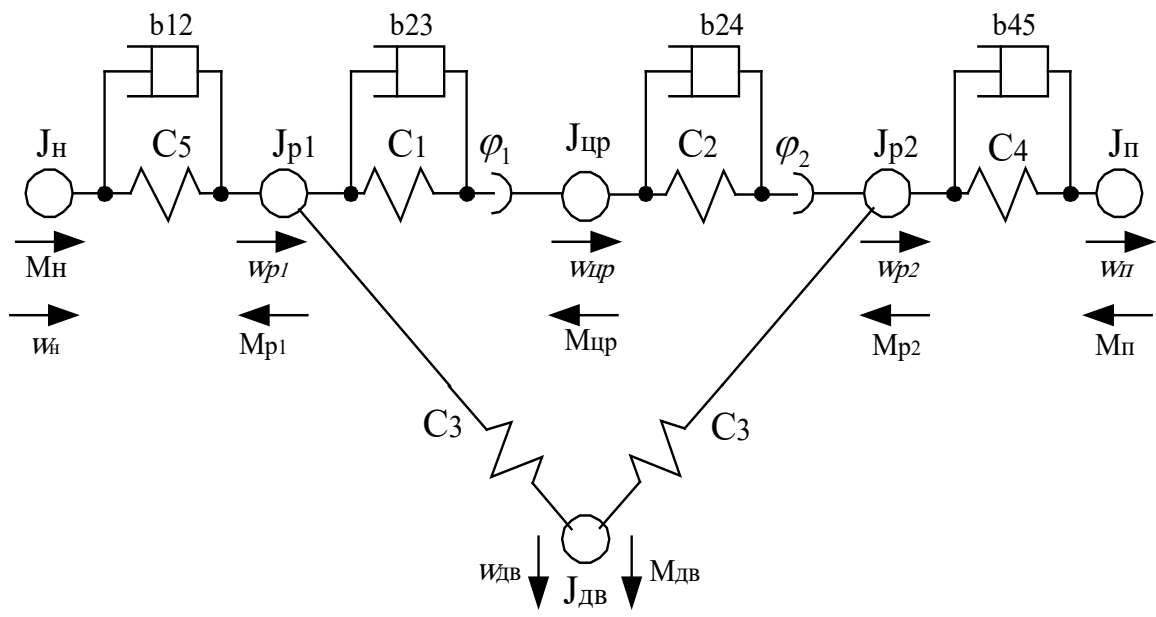

Figure 3. The design diagram of the filled looper follows:

The system of equations for this case will be as 


$$
\begin{aligned}
& M_{u}-M_{12}=J_{u} \frac{d w_{u}}{d t} \\
& M_{12}=c_{5}\left(\varphi_{u}-\varphi_{p 1}\right)+b_{12}\left(w_{u}-w_{p 1}\right) \\
& M_{12}-M_{23}-M_{56}=J_{p 1} \frac{d w_{p 1}}{d t} \\
& M_{56}=c_{3}\left(\varphi_{p 1}-\varphi_{\partial \theta}\right) \approx M_{67}=c_{3}\left(\varphi_{p 2}-\varphi_{\partial \theta}\right) \\
& \left\{\begin{array}{l}
M_{23}=c_{1}\left(\varphi_{p 1}-\varphi_{u p} \pm \varphi_{1} / 2\right)+b_{23}\left(w_{p 1}-w_{u p}\right) \text { if }\left|\varphi_{p 1}-\varphi_{u p}\right|>\varphi_{1} / 2 \\
M_{23}=0
\end{array}\right. \\
& M_{23}-M_{34}=J_{u p} \frac{d w_{u p}}{d t} \quad \text { if }\left|\varphi_{p 1}-\varphi_{u p}\right|<\varphi_{1} / 2 \\
& \left\{\begin{array}{l}
M_{34}=c_{2}\left(\varphi_{u p}-\varphi_{p 2} \pm \varphi_{2} / 2\right)+b_{24}\left(w_{u p}-w_{p 2}\right) \text { if }\left|\varphi_{u p}-\varphi_{p 2}\right|>\varphi_{2} / 2 \\
M_{34}=0
\end{array}\right. \\
& M_{34}-M_{45}-M_{67}=J_{p 2} \frac{d w_{p 2}}{d t} \\
& M_{45}=c_{4}\left(\varphi_{p 2}-\varphi_{n}\right)+b_{45}\left(w_{p 2}-w_{n}\right) \\
& M_{\partial \dot{ }}-M_{56}-M_{67}=J_{\partial \theta} \frac{d w_{\partial \theta}}{d t}
\end{aligned}
$$

$M_{H}, M_{n}, M_{\partial \varepsilon}$ are moments of the strain roll, inflexion roll motors and the looper carriage;

$J_{u}, J_{p 1}, J_{p 2}, J_{u p}, J_{n}, J_{\partial \varepsilon}$ are moments of inertia of the strain roll, roll No. 1, roll No. 2, centering roll, the looper carriage;

$c_{1}, c_{2}, c_{4}, c_{5}$ are rigidities of the strip elastic couplings between masses in corresponding sections;

$c_{3}$ is rigidity of the rope elastic coupling between the carriage drum and the looper carriage;

$\varphi_{H}, \varphi_{p 1}, \varphi_{p 2}, \varphi_{u p}, \varphi_{n}, \varphi_{\partial s}$ are rotational movements of the strain roll, roll No. 1, roll No. 2, centering roll, inflexion roll, the looper carriage;

$\varphi_{1}, \varphi_{2}$ are gaps;

$w_{H}, w_{p 1}, w_{p 2}, w_{u p}, w_{n}, w_{\partial \varepsilon}$ are speeds of rotation of the strain roll, roll No. 1, roll No. 2, centering roll, inflexion roll, the looper carriage;

$M_{12}, M_{23}, M_{34}, M_{45}, M_{56}, M_{67}$ are moment of elastic forces; $b_{12}, b_{23}, b_{24}, b_{45}$ are damping factors.

The rigidity of chain, rope or other parts subjected to tension or compression is defined [25]:

$$
c=\frac{G J_{p}}{l}
$$

$J_{p}$ is the polar moment of cross section inertia, $\mathrm{cm}^{4}$;

$G$ is rigidity modulus of the second kind, $\mathrm{kg} / \mathrm{cm}^{2}$.

The polar moment of inertia of the section for a solid rectangular section is defined according to the formula [25]:

$$
J_{p}=\frac{h^{3} B}{12}
$$

$$
G=\frac{E}{2(1+\mu)},
$$

$\mathrm{E}$ is Young's modulus or rigidity modulus, for steel $\mathrm{E}=2 \cdot 10^{6} \mathrm{~kg} / \mathrm{cm}^{2}$;

$\mu$ - Poisson ratio or transverse deformation coefficient, for steel with elastic deformations $\mu=0.3$.

$$
G=\frac{2 \cdot 10^{6}}{2(1+0.3)} \approx 8 \cdot 10^{5} \mathrm{~kg} / \mathrm{cm}^{2}
$$

The rigidity of the steel strip depends on its geometric dimensions. The width and thickness of the strip during the passing of one coil practically does not change, and the length of the strip changes significantly while moving the loop-forming carriage within the loop device, but it changes almost linearly.

The mass of the strip is defined as:

$$
m_{\text {пол }}=V \cdot \rho=l \cdot h \cdot B \cdot \rho
$$

$\mathrm{V}$ is the volume of the strip, $\mathrm{cm}^{3}$;

1 is the strip length, $\mathrm{m}$;

$\mathrm{h}$ is the thickness of the strip, $\mathrm{m}$;

$\mathrm{B}$ is the width of the strip, $\mathrm{m}$;

$\rho$ is the density of steel, $\rho=7.8 \cdot 10^{-3} \mathrm{~kg} / \mathrm{cm}^{3}$.

According to the Rayleigh principle [26], to take into account the kinetic energy of the strip during the oscillations of the system, it is enough to add one third of the mass of the strip to the mass of the roll.

For example, the moment of inertia of the roll No.1, $\mathrm{kg}$ - $\mathrm{m}^{2}$ :

$$
J_{p 1}=\left(m_{p 1}+m_{1} / 3+m_{2} / 3\right) R_{p 1}^{2}
$$

$\mathrm{m}_{\mathrm{p} 1}$ is the mass of the roll No. $1, \mathrm{~kg}$;

$\mathrm{m}_{1}$ is the mass of the strip from the centering roll to roll No. $1, \mathrm{~kg}$;

$\mathrm{m}_{2}$ is the mass of the strip from roller No. 1 to tension rolls, $\mathrm{kg}$;

$R_{p 1}$ is the radius of the roll No.1, m.

Coefficient of internal viscous friction of elastic elements of mechanical gears of hot rolling mills, $\frac{\mathbb{N}^{x} \mathrm{~ms} s}{\mathrm{rad}}$ [25]:

$$
b=(2 \div 12) \cdot 10^{-4} \cdot c
$$

Based on the system of equations (1), a structural diagram of the horizontal loop device electromechanical system is developed and it is shown in Figure 4. The diagram is supplemented with a direct current electric drive which is made according to a diagram with slave regulation. 


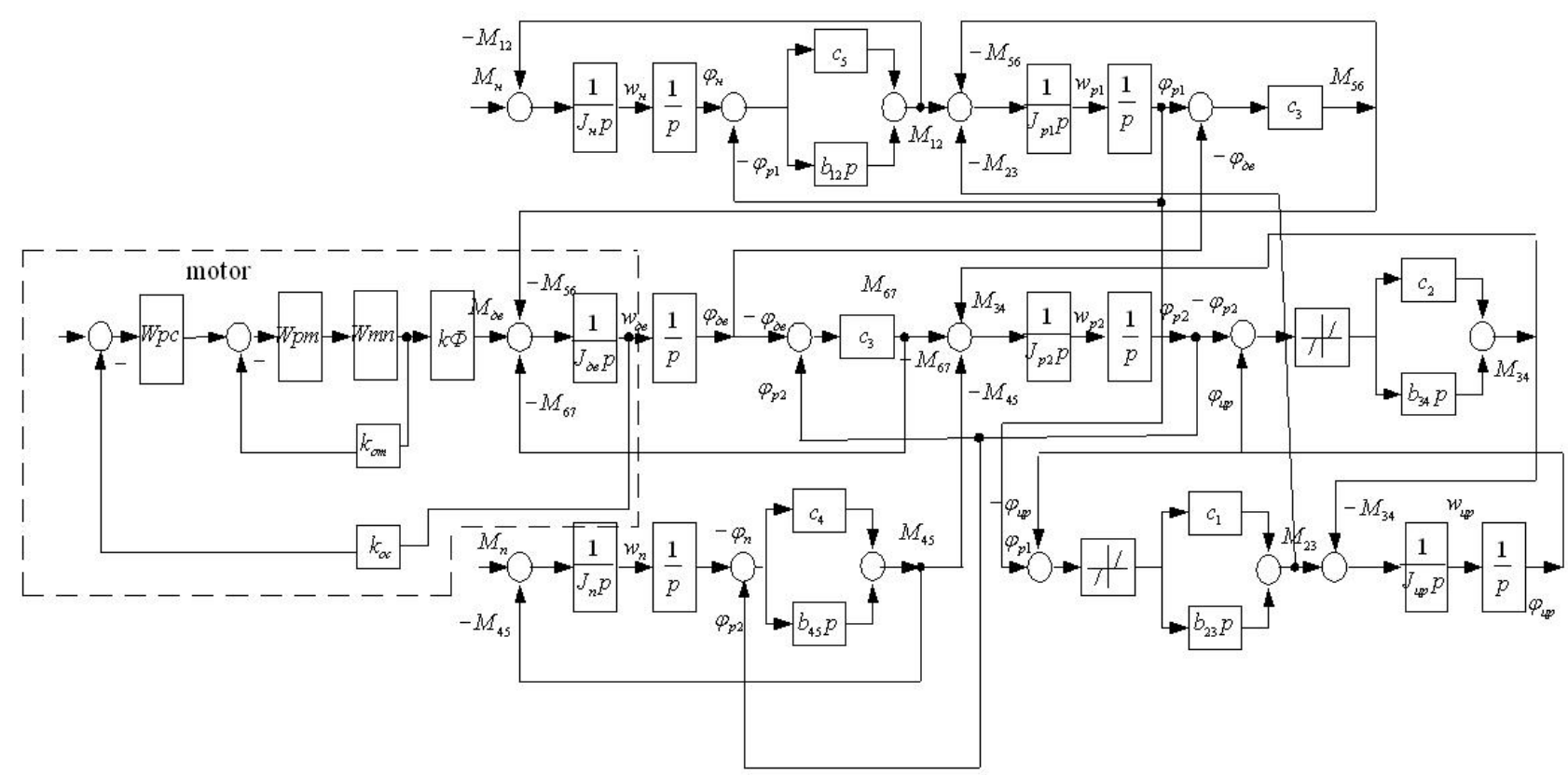

Figure 4. The structural diagram of the filled looper

Let's consider the second case of the work, when the strip is completely removed from the looper (Figure 6).

In this case, when the strip is completely removed from the looper, you can combine the moments of inertia of roller No. 1, roller No. 2 and centering roller into one total moment of inertia, neglecting the length, mass and rigidity of the strip between them. This is due to the fact that in this position the length of the strip is insignificant compared with the case when the looper is completely filled.

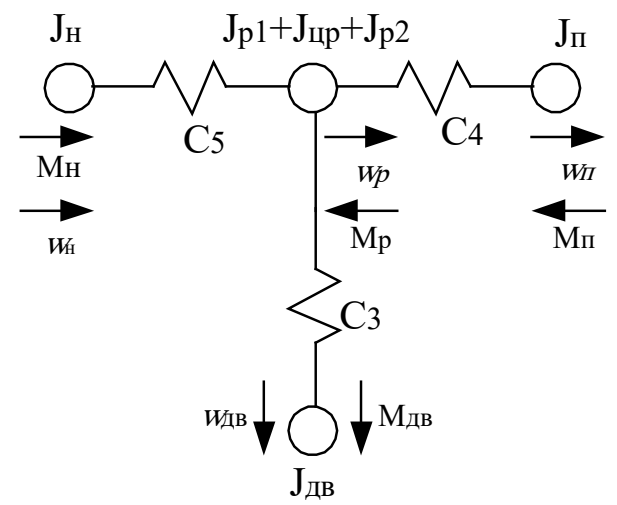

Figure 5. Design diagram of the empty looper
The system of equations for this case will take the following form:

$$
\begin{aligned}
& M_{H}-M_{12}=J_{H} \frac{d w_{H}}{d t} \\
& M_{12}=c_{5}\left(\varphi_{H}-\varphi_{p 1+u p+p 2}\right) \\
& M_{12}-M_{45}-M_{56}=\left(J_{p 1}+J_{u p}+J_{p 2}\right) \frac{d w_{p}}{d t} \\
& M_{45}=c_{4}\left(\varphi_{n}-\varphi_{p 1+u p+p 2}\right) \\
& M_{56}=c_{3}\left(\varphi_{p 1+u p+p 2}-\varphi_{\partial \theta}\right) \\
& M_{\partial \theta}-M_{56}=J_{\partial \theta} \frac{d w_{\partial B}}{d t}
\end{aligned}
$$

The structural diagram of the empty looper is shown in Figure 6. 


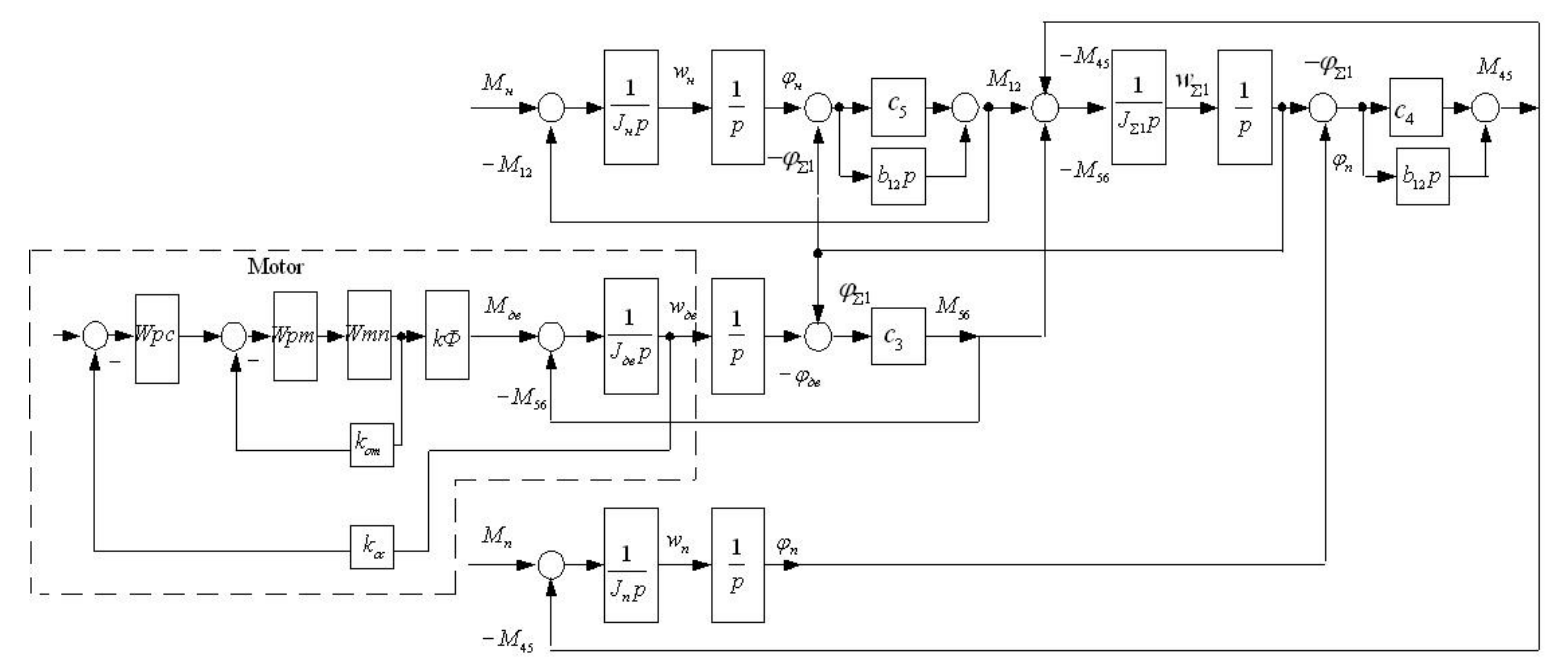

Figure 6. Structural diagram of the empty looper

\section{Results of simulation modeling}

Modeling the electro-mechanical system of a horizontal looper was implemented in the MatLab applied programs package $[27,28]$.
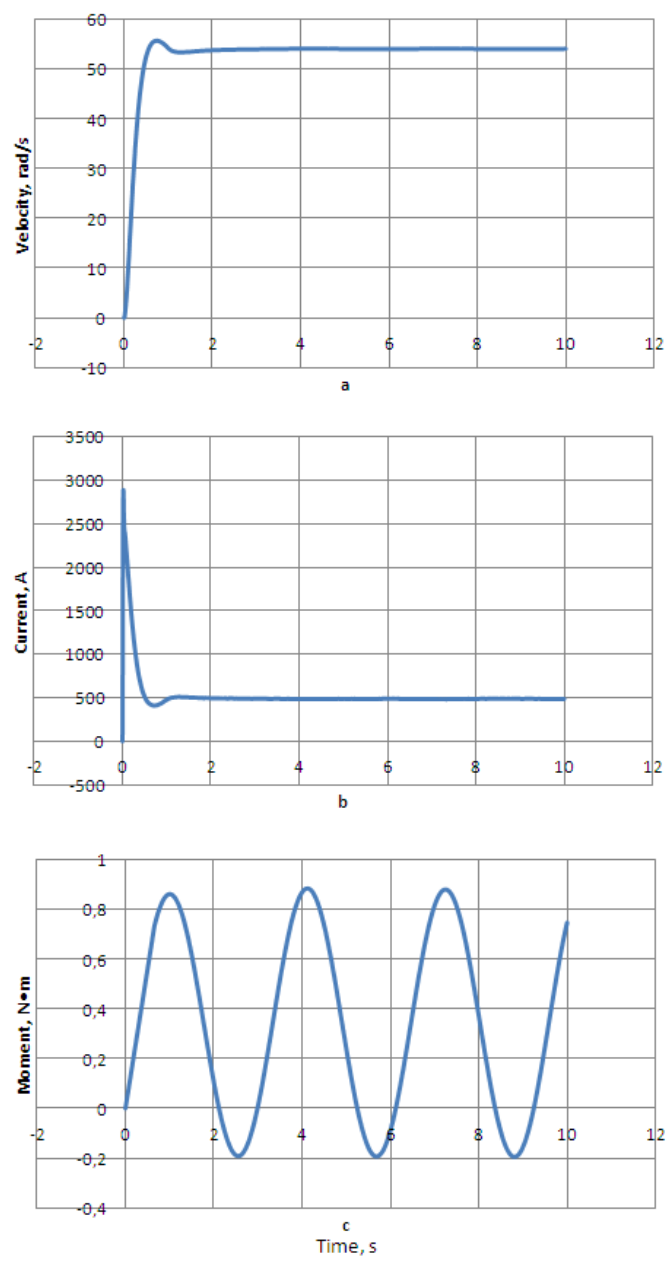

Figure 7. Results of modeling for a completely filled looper
About 20 experiments were carried out. At that time, different operation time of the system was set: from 5 to 90 seconds. Simulation experiments were carried out on models corresponding to the structural diagram of the horizontal loop device electromechanical system shown in Figure 4.

One of the implementations of the experiments is shown in Figure 7. In this case, transients for a fully filled loop device with the largest strip section $2 \times 1700 \mathrm{~mm}^{2}$ are shown. Figure 7 shows the response to the control action on the engine. The graphs show the speed of the motor (a), the current of the motor (b) and the elastic moment (c) between roll No. 2 and the centering roll.

The faithfullness of the simulation model was confirmed by comparison of experimentally obtained data [6]. Transients of current, speed are corresponding to the actual values measured at the unit (aggregate). The amplitude of elastic moment oscillations during simulation experiments can reach $0.882 \mathrm{~N} \cdot \mathrm{m}$ with a filled loop device. The frequency of these oscillations was $0.33 \div 0.48 \mathrm{~Hz}$, it is corresponds to the values recorded at the unit (aggregate).

\section{Discussion of the results}

The complexity of the experiments and the limited possibilities of physical modeling conditioned performing the studies with the use of methods of mathematical and simulation modeling.

The comparison of simulation results and real experiment confirms the compliance of the processes occurring in the model and in the strip at the qualitative level.

In the existing looper only the motor current, linear velocity, and loop reserve in the device are available for measurement.

The analysis of the current carried out in the existing system of visualization and diagnostics of the unit of aluminum zincing "Sofa" shows that changing the length, 
mass and rigidity of the strip has almost no effect on the motor current. This is confirmed by the results of simulation and physical experiments and is explained by a small coefficient of inertia of the drive $\gamma=1.059 \div 1.163$.

In the simulation model oscillations in the strip are present in an explicit form, which is confirmed in the process of simulation experiments.

There were performed about 20 model implementations for different sections of the strip, for an empty and filled looper. Figure 7 shows the graphs for the largest cross-section of a strip for a completely filled device. From the analysis of simulation experiments it was determined that the value of the average current error does not exceed $4 \%$, in terms of speed $3 \%$.

There has been revealed the presence of significant elastic moment oscillations in a completely filled horizontal looper. In this case the amplitude of oscillations amounted to $0.6 \div 0.82 \mathrm{~N} \cdot \mathrm{m}$, and the frequency of oscillations was $0.33 \div 0.48 \mathrm{~Hz}$.

The correspondence of the values of current, speed, amplitude and frequency allows speaking about the quantitative correspondence of the model and the unit.

Good convergence of the results of simulation experiments and measurements in the looper allows drawing the conclusion about the adequacy of the model.

One of the rational methods of damping elastic oscillations is the synthesis of the structure and the choice of control system parameters, since it is relatively easy to implement, can be used for any electromechanical system and does not require additional material costs [29, 12].

The following main methods are considered for use in the synthesis of control systems [12, 29, 30, 22]:

- correction of the gain of the speed controller in the slave control system;

- creating a slave control system with the adding of feedback on the derivative of the speed of the actuator.

- creation of a slave control system with the adding of feedback on the second derivative of the speed of the actuator;

- creation of a slave control system with the adding of additional feedbacks on the difference of speeds between the engine and the actuator;

- creation of a control system with a modal controller;

- creation of a control system using a band-stop filter in the speed control loop;

- using of parallel correction with indirect measurement of the speed of the actuator and using flexible feedback connected to the input of the current regulator;

- creation of a slave control system using additional parallel correcting devices.

As a result of the carried out studies it was established that the existing electric drive system made on the principle of subordinate regulation, does not provide damping of the strip oscillations. This can be confirmed by theoretical studies in this area [29, 31], since for the existing structure due to a small coefficient of inertia and insignificant impact of the strip dynamics on the parameters of the electric drive it is impossible to provide suppression of elastic oscillations.

Based on the analysis of the performed experiments, the conclusion about elastic properties of the strip, which are practically do not appear with an empty horizontal loop device, is confirmed. The elastic properties of the strip appear with a large length, i.e. when the horizontal loop device is full. A great influence on the dynamic parameters is exerted by the mass of the strip.

As can be seen from the results of simulation, oscillations in the mechanical part of the HLD practically do not affect the electric drive. This is explained by a large gear ratio and a low inertia coefficient. For damping oscillations of systems having such an inertia coefficient $(1.059 \div 1.163)$ [32], the use of standard slave control systems is inefficient. Increasing the sensitivity of the system can be achieved by expanding the bandwidth of the electromechanical system. Bandwidth expansion is possible by adding feedbacks to the coordinates of the band. In this case, it becomes necessary to adapt the parameters of the control system to a changing coefficient of inertia.

\section{Conclusion}

A mathematical model of the electromechanical system of a horizontal loop device has been developed taking into account the mechanical properties of the strip for two positions: for an empty and a filled device.

With an empty horizontal loop device, elastic oscillations are practically absent. With a full horizontal loop device, elastic oscillations with a significant amplitude occur.

Simulation experiments were carried out, as a result the conclusion that this control system does not provide damping of oscillations in the band due to the small coefficient of inertia was confirmed.

Further work will be aimed on creating a new electric drive system that provides damping of elastic oscillations using electrical methods.

\section{References}

[1] Opeiko O.F. (2009) Control of an Electric Drive for a Continuous Material Processing Unit. Russian Electrical Engineering, Vol. 80, No. 2, pp. 74-77

[2] Parshin V.S., Bogolyubova D.D. Analiz konstruktsii nakopiteley ploskoy polosyi nepreryivnyih agregatov. http://econf.rae.ru/pdf/2012/10/1707.pdf

[3] Vasilev A.G. (1972) Nakopiteli polosyi agregatov podgotovki i otdelki $\mathrm{v}$ tsehah holodnoy prokatki v SSSR i za rubezhom. M. - NIIinformtyazhmash. -17 p.

[4] Limonov L.G. (2009) Avtomatizirovannyiy elektroprivod promyishlennyih mehanizmov. Harkov, Fort,-272 p.

[5] Yudin A. Yu. (2006) Sovershenstvovanie sistem upravleniya vzaimosvyazannyimi elektroprivodami vhodnogo uchastka agregata nepreryivnogo goryachego tsinkovaniya. Spetsialnost 05.09.03 - Elektrotehnicheskie 
kompleksyi i sistemyi. Avtoreferat dissertatsii na soiskanie uchenoy stepeni kandidata tehnicheskih nauk. Magnitogorsk - $22 \mathrm{p}$.

[6] Kazantsev V.P. \& Dadenkov D.A. (2012) On the synthesis of discrete-continuous control systems with elastic-dissipative links for electric drives. Russian Electrical Engineering, Vol, 83, No. 11, pp 605-608

[7] Neto M.A., Ambrósio J.A.C., Roseiro L.M. et al. (2013) Active vibration control of spatial flexible multibody systems. Multibody System Dynamics, Vol. 30, No. 1, pp 13-35

[8] Nguyen V.K., Nguyen P.D. \& Hoang M.C. (2009) Linearization and parametric vibration analysis of some applied problems in multibody systems. Multibody System Dynamics, Vol. 22, No. 2, pp 163-180.

[9] Limonov L.G. (2009) Automated electric drive of industrial mechanisms. Kharkiv, Fort, 272 p.

[10] W. Wójcik, O. Yuchshenko (2014) Development of simulation model of strip pull self-regulation system in dynamic modes in a continuous hot galvanizing line. Informatyka, Automatyka, Pomiary. - Wydawnictwo: Centrum Innowacji I Transferu Technologii LPNT. Lublin Polska,. - № 1. - pp. 11-13.

[11] Breido I.V., Sivyakova G.A. (2002) Experimental researches of interconnected electric drives of a continuous annealing unit. Abstracts of the III international scientific and technical conference. - Almaty, $528 \mathrm{p}$.

[12] Malafeev, S.I., Malafeeva, A.A. \& Konyashin, V.I. (2018) An electrical feed drive-control system for a cold reducing mill. Russian Electrical Engineering, Vol. 88, No. 4, pp 205-208

[13] Erkaya, S. (2019) Determining power consumption using neural model in multibody systems with clearance and flexible joints. Multibody System Dynamics, Vol. 47, No. 2, pp 165-181

[14] Mazunin V.P., Dvoinikov D.A. (2010) Parameteric Limitations in Nonlinear Control Systems of Mechanisms with Elasticity. Russian Electrical Engineering, , Vol. 81, No. 5, pp. 227-231.

[15] Sapronov K. A., Cherepanov A. A., Yatsun S. F. (2010) Investigation of Motion of a Mobile Two Mass Vibration_Driven System. Journal of Computer and Systems Sciences International, Vol. 49, No. 1, pp. 144 151.

[16] Polyakov A.E., Polyakov K.A., Pavlov N.K., Seryakov I.N. and Kozlova L.A. (2010) Effect of the elasticity of the mechanical part of an extruder takeup shaft on the dynamic characteristics of the electric drive. Fibre Chemistry, Vol. 42, No. 1, pp 63-67.

[17] Radionov A.A., Karandaev A.S., Khramshin V.R., Evdokimov A.S., Andryushin I.Yu., Gostev A.N., Shubin A.G., Gasiyarov V.R. (2015) Mathematical Modelling of the Interrelated Electric and Mechanical Systems of Continuous Sub-Group of the Rolling Mill Stands. Part 2. Study of Dynamic Loads in the Universal Mill Stands. Bulletin of the South Ural State University. Ser. Power Engineering, vol. 15, no. 2, pp. 67-76.

[18] Precup, RE., Lee, W.S., Rao, M.V.C. et al. (2008) Linear and fuzzy control solutions for tape drives. Electrical Engineering, Vol. 90, No. 5, pp 361-377.

[19] Nazarova E.S. (2015) Matematicheskoe modelirovanie elektromehanicheskih sistem stanov holodnoy prokatki. TehnIchna elektrodinamIka. No. 5. - pp. 82-89.

[20] Rong, B., Rui, X., Tao, L. et al. (2019) Theoretical modeling and numerical solution methods for flexible multibody system dynamics. Nonlinear Dynamics, Vol. 98, No. 2, pp 1519-1553

[21] Sass, L., McPhee, J., Schmitke, C. et al. (2004) A Comparison of Different Methods for Modelling Electromechanical Multibody Systems. Multibody System Dynamics, Vol. 12, No. 3, pp 209-250

[22] Breido, J., Sivyakova, G. \&Gurushkin A. (2016). The Modernization of the Multimotor Electric Drives. DAAAM INTERNATIONAL SCIENTIFIC BOOK, pp. 375-392 Chapter 34.

[23] Ruderman M., Aranovskii S.V., Bobtsov A.A., Bertram T. (2012) Nonlinear Dynamics of Drives with Elasticities and Friction. Automation and Remote Control, , Vol. 73, No. 10, pp. 1604-1615.

[24] Breido I.V., Kuntush E.V. (2005) Razrabotka matematicheskoy modeli elektromehanicheskoy sistemyi gorizontalnogo petlevogo ustroystva. Trudyi universiteta No.1,- pp. 76-79 .

[25] Feodosiev V.I. (1986) Strength of materials. - M., Science,. $-512 \mathrm{p}$.

[26] Vakhitov S.Y., Basharin S.A., Smirnova N.A., Shchitov I.N. (2015) Analytical model and calculating method of the oscillatory system of dynamic dome-type converters. Basic research. No. 7-3. - pp. 511-516

[27] Ob'ekt avtorskogo prava \#247 ot 22.10.2018 g. Programma dlya EVM. Imitatsionnaya model elektromehanicheskoy sistemyi gorizontalnogo petlevogo ustroystva stana holodnoy prokatki./ Kuntush E.V., Breido I.V.

[28] Yin, F., Sun, J., Peng, W. et al. (2017) Dynamic matrix predictive control for a hydraulic looper system in hot strip mills. Journal of Central South University, Vol. 24, No. 6, pp 1369-1378

[29] Kozhevnikova I.A., Kozhevnikov A. V., Sorokin G. A., Markushevskii N. A. (2016) Damping of Vibrations in the Primary Drives of Cold-Rolling Mills. Steel in Translation, Vol. 46, No. 10, pp. 739-741.

[30] Gannel', L. V. (2013) Built In Filters to Suppress Vibrations in a Linear Elastic Electric Drive on Account of Reduction in the Effective Mass. Russian Electrical Engineering, Vol. 84, No. 3, pp. 145-148.

[31] Aghababa, M.P. (2019) Fractional-calculus-based control scheme for dynamical systems with input uncertainty. Advances in Difference Equations, 2019:391.

[32] Klyuchev V.I. (1971) Limitation of dynamic loads of the electric drive. M., Energy, - 320 p. 